\title{
Cladistics
}

\section{Phylogeny of Maculinea blues (Lepidoptera: Lycaenidae) based on morphological and ecological characters: evolution of parasitic myrmecophily}

\author{
Pavel Pech ${ }^{1}$, Zdeněk Fric ${ }^{1,2, *}$, Martin Konvička ${ }^{1,2}$ and Jan Zrzavý1, \\ ${ }^{1}$ Department of Zoology, Faculty of Biological Sciences, University of South Bohemia, Branišovská 31, CZ-37005 České Budějovice, Czech Republic; \\ ${ }^{2}$ Institute of Entomology, Academy of Sciences of the Czech Republic, Branišovská 31, CZ-37005 České Budějovice, Czech Republic
}

Accepted 13 July 2004

\begin{abstract}
A phylogeny of blue butterflies of the genus Maculinea and related genera (Lycaenidae) is proposed, based on 91 morphological and ecological characters. The resulting tree shows that: (1) Phengaris is a derived group nested within Maculinea; (2) the MaculineaPhengaris clade is probably nested within Glaucopsyche; (3) there are three well supported groups within the Maculinea-Phengaris clade: (alcon group ((teleius group) (arion-Phengaris group))). Some species (M. alcon, M. arionides) appear to be non-monophyletic and require reclassification. The two alternative strategies of parasitic myrmecophily in the Maculinea-Phengaris clade, viz., "predatory" and "cuckoo", seem to be derived characters of the alcon group, and of the teleius and arion-Phengaris groups, respectively. The common ancestor of Maculinea used dorsal nectary organ secretions for ant attraction, while this trait was reduced in the ancestor of the alcon group and in $M$. nausithous (of the teleius group). The three recent Maculinea lineages utilize taxonomically diverse host plants, the asterid families Gentianaceae (alcon and arion-Phengaris groups), Lamiaceae (arion-Phengaris group), Campanulaceae (arion-Phengaris group), and the rosid family Rosaceae (teleius group).
\end{abstract}

(c) The Willi Hennig Society 2004.

The blues of the genus Maculinea Van Eecke, 1915 (Lepidoptera: Lycaenidae) belong to the most intensively studied butterflies in Eurasia. In contrast to the vast majority of myrmecophilous lycaenid butterflies who receive protection from ants, Maculinea species have evolved an intricate form of nest parasitism. Their early larval instars are mono- to oligophagous feeders on flowers and developing seeds of herbs, but later parasitize the nests of ant genera Myrmica Latreille, 1804, and Aphaenogaster Mayr, 1853 (see, e.g., Fiedler, 1991; Wardlaw et al., 2000). This ecological complex has attracted much research on butterfly myrmecophily (e.g., Hochberg et al., 1994; Fiedler, 1998; Akino et al., 1999; Pierce et al., 2002). Maculinea have also been intensively studied by conservation biologists, since their specialized habits render them vulnerable to habitat alteration; they have exhibited severe declines in Europe (Wynhoff, 1998a; Van Swaay and Warren, 1999). The

*Correspondence: E-mail address: zdenek.fric@tix.bf.jcu.cz extinction of Maculinea arion (Linnaeus, 1758) in the UK in the 1970s (Thomas, 1980) has in fact sparked interest in the scientific conservation and habitat restoration of butterflies (e.g., Elmes and Thomas, 1992; Hochberg et al., 1994; Thomas, 1994; Wynhoff, 1998b). It is therefore rather odd that there is still a lack of knowledge about phylogenetic relationship within the genus. This complicates our understanding of the origin and evolution of Maculinea parasitic development (Elmes et al., 2001; Als et al., 2002). It also causes controversies in terms of the taxonomic status of individual taxa, including those with a high conservation priority. Specifically, there are controversies concerning the status of $M$. alcon (Denis \& Schiffermüller, 1775) and M. rebeli (Hirschke, 1904), two threatened European taxa, which spend the early phases of their development on Gentianaceae plants (compare Sibatani et al., 1994; Kudrna, 2001).

Regarding parasitic myrmecophily, Maculinea species vary in two conspicuous traits: the adoption ritual, and 
the mode of larval feeding within the ant nests. Adoption may or may not include the use of secretions from the dorsal nectary organ (DNO) for enticing the attention of ants. While in ant nests, the larval feeding may either be: (1) "cuckoo" when the ants feed the caterpillars via regurgitation, or (2) "predatory" when the caterpillars prey on ant broods. Since the species of Maculinea that employ the DNO secretions during adoption tend to be predatory (Table 1), and DNO secretions play a major role in mediating mutualism with ants in the majority of related non-parasitic genera of lycaenid butterflies, the predatory habit was proposed as ancestral for the genus (Fiedler, 1998). Further arguments corroborating the claim that cuckoo caterpillars are derived, include a lower fitness cost imposed upon the ants by cuckoos, shorter adoption time, and a more elaborate communication between the cuckoo caterpillars and ants (Fiedler, 1990, 1998; Elmes et al.,
1991, 2002; Thomas and Elmes, 1998). In addition, several putative non-parasitic Maculinea outgroups feed on Lamiaceae, which are also utilized by the predatory species $M$. arion and $M$. arionides. Fiedler (1998) suggested that the ancestor of Maculinea evolved in high-altitude steppe-like habitats with a long unfavorable season, which forced it to spend part of its development within ant nests.

At this time, it is uncertain how closely individual species of Maculinea are associated with individual species of ants. The associations were considered highly specific by Thomas et al. (1989), but recent studies (e.g., Wardlaw et al., 1998; Steiner et al., 2003) have suggested that the situation is much more complex (Als et al., 2002). Therefore, we have refrained from including ant specificity characters in our phylogenetic analyses.

The purpose of this paper is to test the above hypotheses of the evolution of parasitic myrmecophily

Table 1

List of terminals used for the analysis, their host plant associations, geographic distribution, and associations with ants. Species investigated by present authors are presented in bold typeface

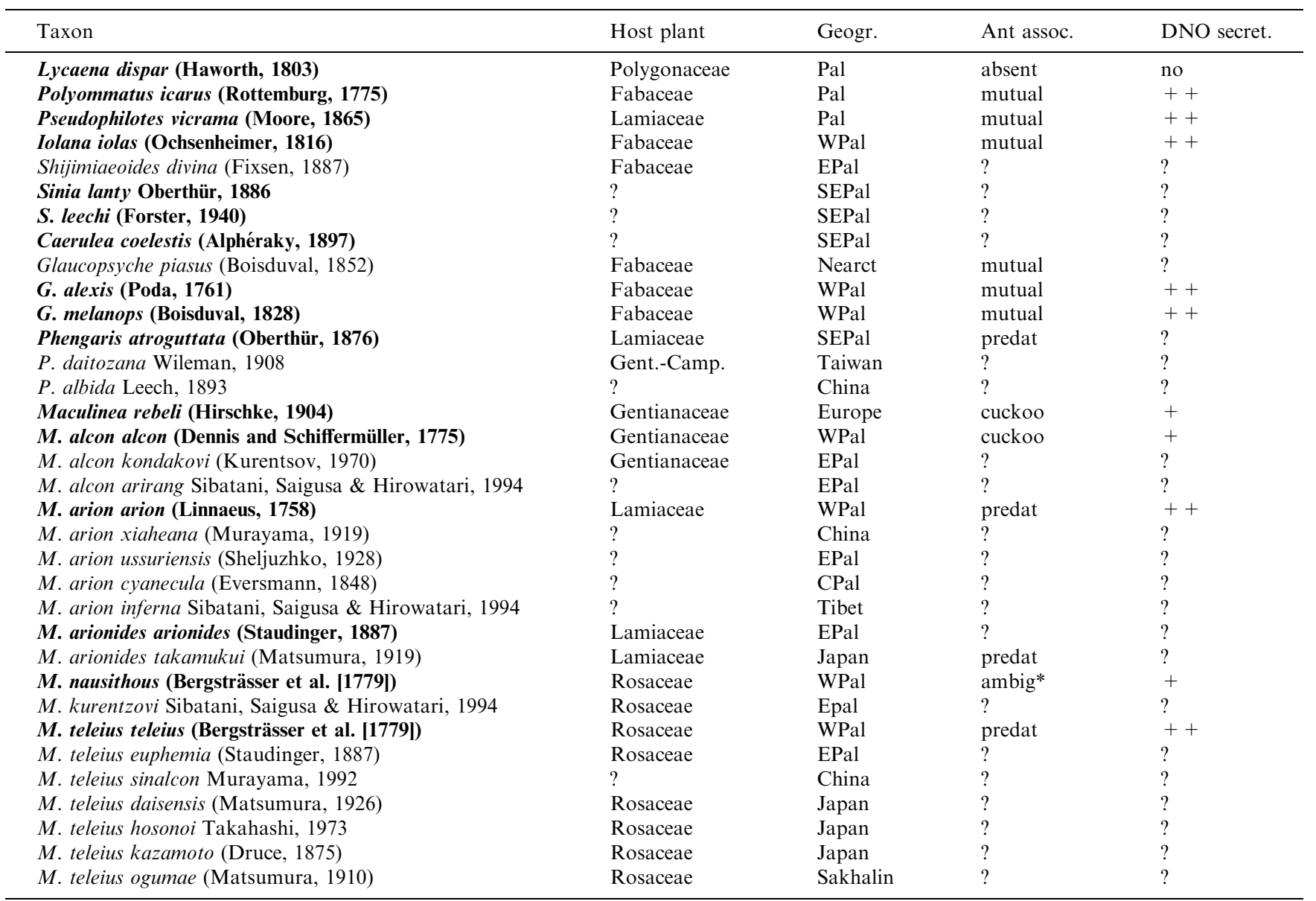

See Material and Methods; Host plant: Gent., Gentianaceae; Camp., Campanulaceae; Geogr., geographic distribution: Pal, Palearctics; Nearct, Nearctics; E, east; W, west; SE, south-east; C, central; Ant assoc., type of ant association: mutual, mutualistic; predat, predatory; DNO secret., dorsal nectary organ secretion: + , rare; ++ , frequent. 
in Maculinea, using a cladistic hypothesis based on morphological and ecological data, and to reconstruct the history of: (i) the use of DNO secretions during adoption, (ii) predatory versus cuckoo feeding, (iii) host plant use, and (iv) habitat preferences of individual species.

\section{Materials and methods}

\section{Taxonomy}

Maculinea is distributed across the Palaearctic region and consists of a minimum of seven species (Sibatani et al., 1994; Table 1). The most closely related genera include Bajluana Korshunov, 1990, Caerulea Forster, 1938, Euphilotes Mattoni, 1977; Glaucopsyche Scudder, 1872, Iolana Bethune-Baker, 1914, Micropsyche Mattoni [1981], Otnjukovia Zhdanko, 1997, Paleophilotes Forster, 1938, Phengaris Doherty, 1891, Philotes Scudder, 1876, Philotiella Mattoni, 1977; Praephilotes Forster, 1938, Pseudophilotes Beuret, 1955, Scolitantides Hübner, 1819, Shijimiaeoides Beuret, 1955, Sinia Forster, 1940, Subsulanoides Koiwaya, 1989 (only provisionally placed here), and Turanana Bethune-Baker, 1916; all being classified as members of the "Glaucopsyche-section" of Lycaenidae: Polyommatini (Eliot, 1973; Mattoni, 1977, 1979[1981]). Hesselbarth et al. (1995) proposed the division of this section into two lineages: Scolitantiditi, including Scolitantides and Pseudophilotes; and Glaucopsychiti, including Glaucopsyche (sensu lato, i.e., including Maculinea and Iolana), Turanana and Lachides.

Given the confused state of Maculinea alpha-taxonomy, we refrained from resolving specific taxonomic controversies before selecting terminal taxa for the cladistic analysis and included the nominal taxa regardless their formal "species" or "subspecies" ranks. We focused on: (1) all the "established" European species, recognized in recent mainstream lepidopterist literature (e.g., Karsholt and Razowski, 1996; Wynhoff, 1998b) and (2) the Asian taxa revised by Sibatani et al. (1994) (Table 1).

In selecting outgroup taxa, we tried to represent the diversity of the Glaucopsyche-section by including: (i) some representatives of both of the lineages, Scolitantiditi and Glaucopsychiti, recognized by Hesselbarth et al. (1995); (ii) representatives of all genera that were considered congeneric with Maculinea by recent authors (e.g., Cano, 1981; Bálint, 1989); (iii) all three representatives of East-Asian Phengaris, the only other genus of the Glaucopsychiti exhibiting parasitic myrmecophily (Fiedler, 1998; Elmes et al., 2001; Pierce et al., 2002); (iv) Polyommatus icarus (Polyommatini) and Lycaena dispar (Lycaenini) as more distant lycaenid butterflies. The nomenclature and higher classification of
non-Maculinea taxa follow Eliot (1973) and Tolman and Lewington (1997).

\section{Character sampling}

The characters used in the phylogenetic analysis (for the list of characters see Appendix 1; for the data matrix Appendix 2) were extracted from literature, as well as from our study of the morphology of collection specimens ("orig." hereinafter). The terminalia characters ( $N=37$; sources Hemming, 1931; Beuret, 1958; Shirozu, 1960; Agenjo, 1967; Bernardi, 1972; Eliot, 1973; Higgins, 1975; Kawazoe and Wakabayshi, 1976; Mattoni, 1977; Mattoni and Fiedler, 1991; Sibatani et al., 1994; Jaksic, 1998; orig.) were coded according to Sibatani et al. (1994). Wing color pattern traits $(N=$ 34; from Shirozu, 1960; Kurentsov, 1970; Kawazoe and Wakabayshi, 1976; Inomata, 1990; D'Abrera, 1993; Sibatani et al., 1994; Korshunov and Gorbunov, 1995; Tuzov et al., 2000; Berlov, 2001; orig.) were coded using a combination of the "Nymphalid Ground Plan", a diagrammatic system for identifying individual pattern elements across the Lepidoptera (Nijhout, 1991), and the codes for wing spots shown in Fig. 1. According to numerous morphological, developmental, and genetic studies (for recent reviews see Beldade et al., 2002;

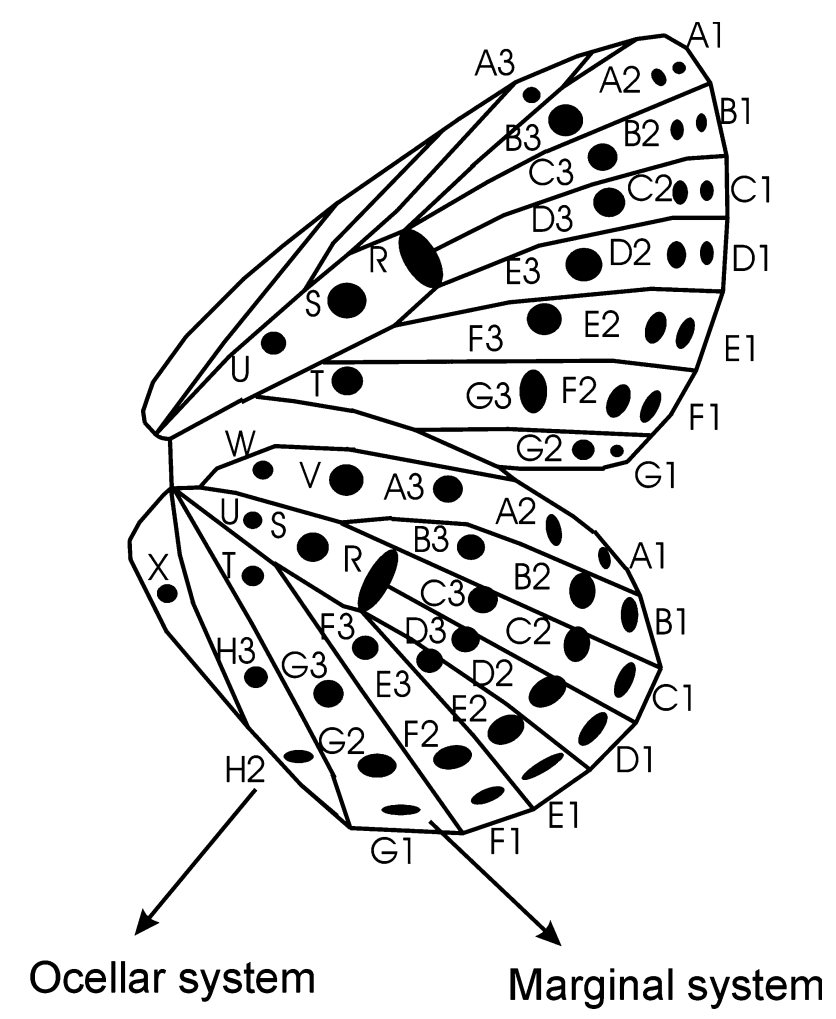

Fig. 1. System of coding of wing pattern traits used in the phylogenetic study of Maculinea and their relatives. 
Brakefield, 2003) the individual wing pattern elements evolve in a more or less independent manner, which justifies treating them as separate characters in the cladistic analyses. Additional characters concerned the eyes $(N=1$; Higgins, 1975 ; orig. $)$, labial palps $(N=2$; Mattoni, 1977 ; orig.), antennae $(N=2$; orig.), wing venation $(N=1$; Higgins, 1975), eggs and hatching ( $N=3$; Fukuda et al., 1985; Thomas et al., 1991), and life history $(N=11$; Kurentsov, 1970; Emmet and Heath, 1989; Ebert and Rennwald, 1991; Fiedler, 1991; Thomas et al., 1991; Leimar and Axén, 1993; Korshunov and Gorbunov, 1995; Park and Kim, 1997; Fiedler, 1998; Igarashi and Fukuda, 2000; Beneš et al., 2002; Pierce et al., 2002).

\section{Cladistic methods}

We used the maximum parsimony program NONA version 2.0 (Goloboff, 1999), with heuristic search strategy option "hold 1000000; mult*100; hold/100; mult*; max*", to identify the optimal phylogenetic hypothesis. Tree support was calculated with the bootstrap (NONA: 1000 replications, option "mult*100; hold/100") and Bremer support (NONA: "bsupport 100000").
We used parsimony optimization (option "unambiguous" in NONA) to map onto the optimal tree hypothesis the alternative adoption rituals (nos. 84-85 in Appendix 1), larval feeding habits (no. 86), the phylogenetic positions of host plants (no. 80, from Angiosperm Phylogeny Group, 2003), and habitat association (no. 90). The tree topology was tested against the inclusion/exclusion of some characters whose cladistic usefulness seems to be disputable (no. 52, 88, 90).

\section{Results}

Phylogeny of Maculinea

The analysis based on the entire data matrix yielded four equally most parsimonious trees (length $=306$, consistency index $[\mathrm{CI}]=0.33$, retention index $[\mathrm{RI}]=$ 0.63). In the strict consensus (Fig. 2), Maculinea forms a well-supported group, paraphyletic with respect to Phengaris (hereafter "Maculinea clade"). It is characterized by two unique synapomorphies, both ecological (parasitic myrmecophily, and an obligate association with one ant family, i.e., Myrmicidae). In addition, the group is supported by a short third segment of palps,

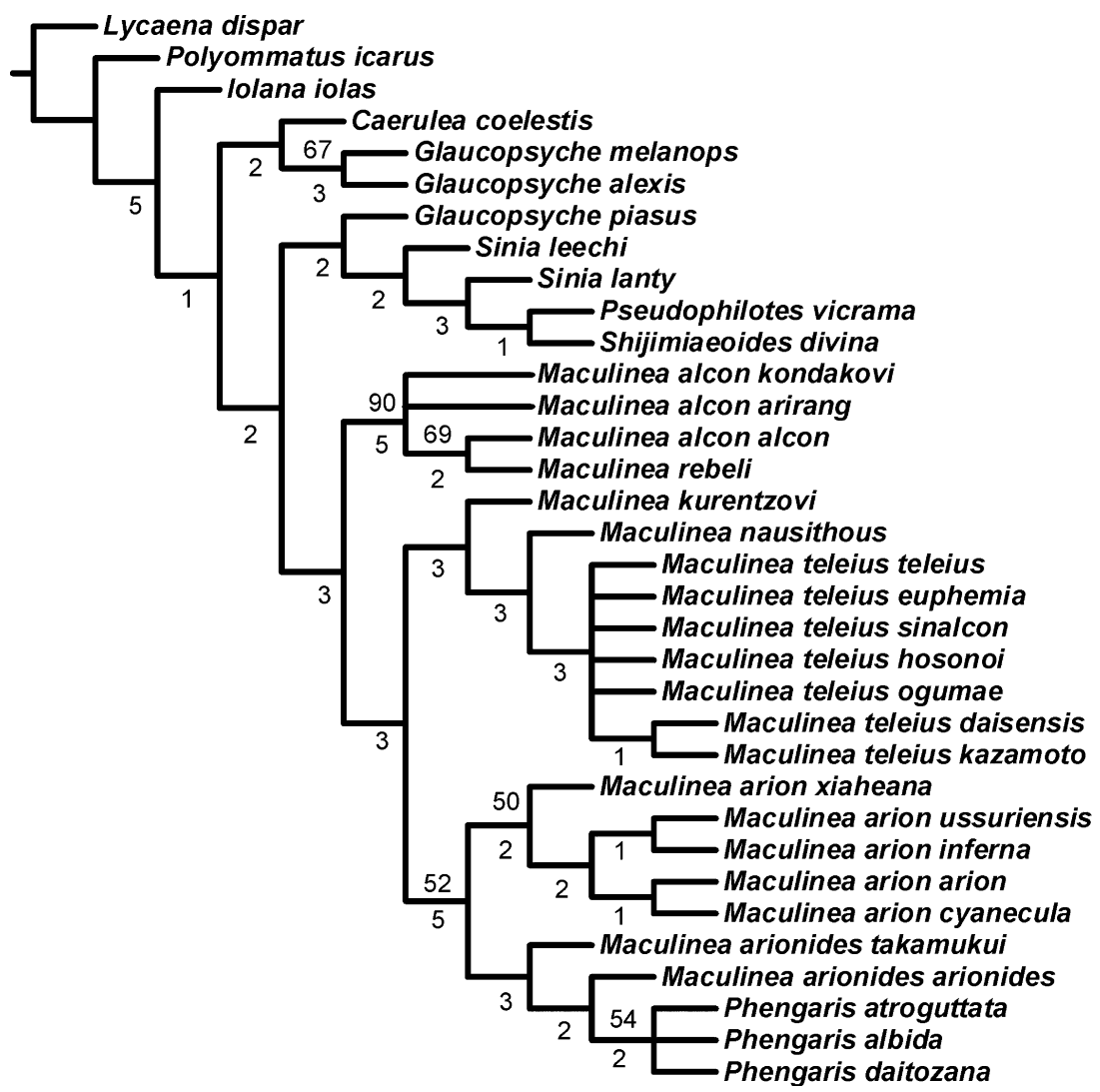

Fig. 2. Strict consensus of the four equally most parsimonious trees (length 306, CI 0.33, RI 0.63) showing proposed phylogenetic relationships within the "Glaucopsyche-section" of Lycaenidae: Polyommatini. Bootstrap and Bremer support are shown above and below the nodes, respectively. 
stalk of forewing veins $7+8$ arising at the end of a discoidal cell, and larva overwintering (Fig. 3). Outside the Maculinea clade, Glaucopsyche becomes paraphyletic: $G$. piasus belongs to a sister group of Maculinea, which includes Sinia, Shijimiaeoides and Pseudophilotes, whereas $G$. melanops and $G$. alexis form a more basal clade with Caerulea coelestis.

The Maculinea clade is divided into three wellsupported subgroups. The basal-most is identical to the "alcon group" of Sibatani et al. (1994); it is followed by the "teleius group" and the "arion group" (including all three species of Phengaris in the latter). The alcon group shares five synapomorphies, all genitalic, two being unique to the group (Fig. 3). M. rebeli is situated amidst individual "subspecific" taxa of $M$. alcon, as sister to $M$. alcon alcon. The $M$. teleius-arion clade shares five synapomorphies, four of them genitalic and one concerning the position of eggs on the host plant. Two of the genitalic characters are unique to the clade. Within the teleius group, M. kurentzovi branches off in the basal position; the clade then splits into $M$. nausithous and a monophyletic cluster of putative subspecies of $M$. teleius. The arion group is characterized by three genitalic and two wing pattern character states. Within the arion group, $M$. arionides seems to be paraphyletic with respect to Phengaris.

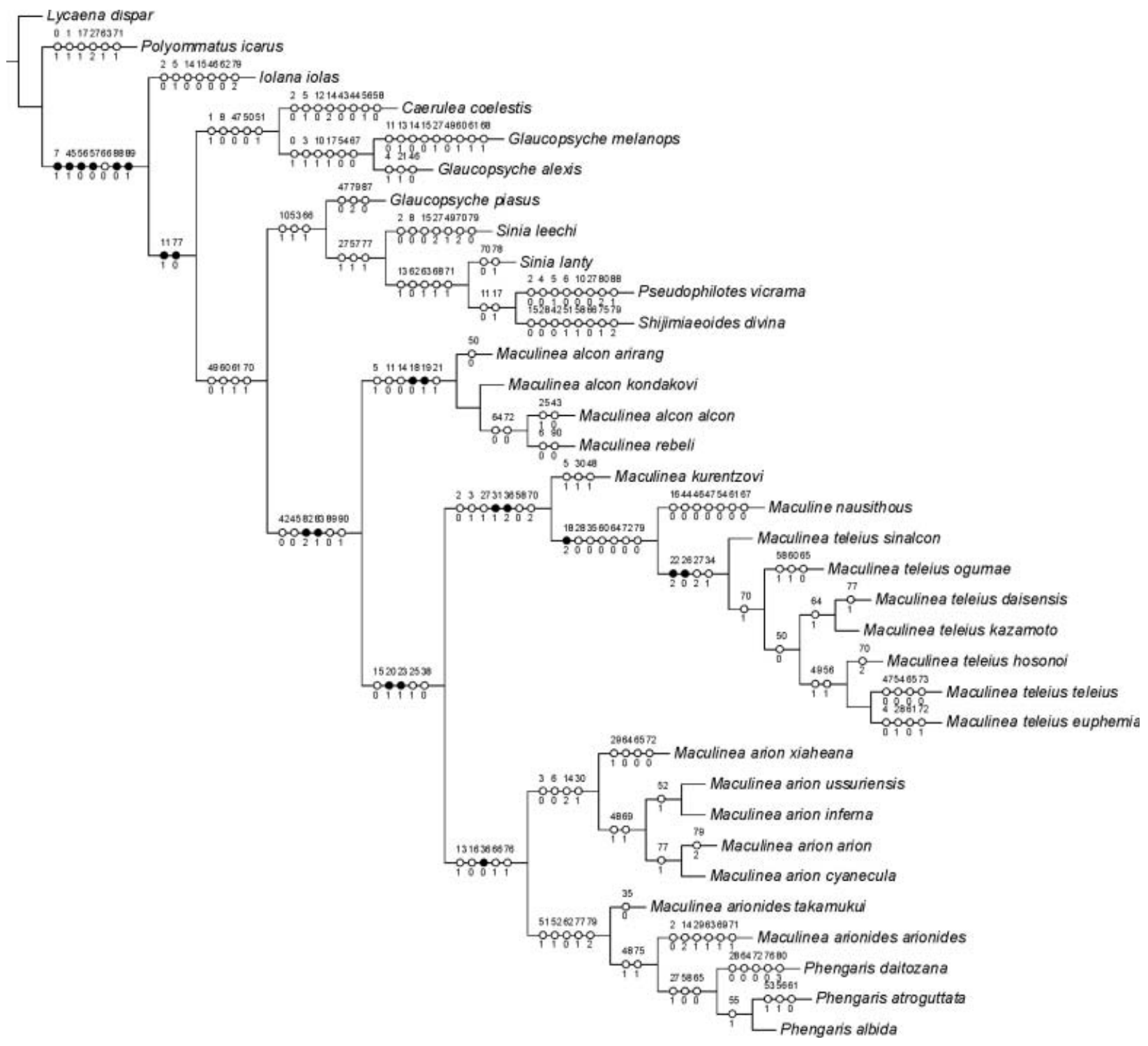

Fig. 3. One of the four equally most parsimonious trees (length 306, CI 0.33, RI 0.63; chosen at random: individual source trees differ only in position of terminals within Phengaris, M. teleius and $M$. alcon group: see Fig. 2), with character states that support individual clades. Nonhomoplastic autapomorphies are black, homoplastic apomorphies white. Numbers above branches refer to characters, numbers below branches to character states (see Appendix 1 for character descriptions). 
The distribution of apomorphies in the combined tree suggests that terminalia are better at resolving deeper branches than wing patterns, the latter character set being most informative at the specific and subspecific levels (Fig. 3). Only three deeper nodes (M. nausithousteleius clade, $M$. arionides-Phengaris clade, and Phengaris) are determined partly or exclusively by the wing-pattern characters. The ecological and life-history characters contribute little to the deep nodes of a tree, with a single but important exception: the monophyly of the Maculinea clade is mostly corroborated by the butterflies' ecology.

\section{Evolution of life histories}

Parsimony optimization of the presence/absence of the secretion from the dorsal nectary organ (no. 85 in Appendix 1) indicated that use of the DNO secretions during adoption is an ancestral state, which was subsequently lost in the alcon group, and either lost or reduced in $M$. nausithous.

Regarding larval feeding (no. 86), we failed to find an unequivocal solution for the origin of predatory and cuckoo habits. The character state is ambiguous in the ancestor of the Maculinea clade (Fig. 4A), and it is only certain that the ancestor of the Maculinea clade already exhibited obligate parasitic myrmecophily and that the cuckoo and predatory habits evolved in two distinct lineages of the clade. Treating the feeding habit of $M$. nausithous as predatory (or as polymorphic), the optimization of this character on the resulting tree results in three equally most parsimonious solutions: (i) independent origin of cuckoo and predatory habits, (ii) ancestral predatory habit changed into cuckoo in the alcon group, and (iii) ancestral cuckoo habit changed into predatory in the shared ancestor of arion and teleius groups. Only if $M$. nausithous was recoded as being a cuckoo did two possibilities appear: (i) the origin of predatory habit in the ancestor of the Maculinea clade, followed by two changes to the cuckoo habit, in the alcon group and in M. nausithous; and (ii) the cuckoo habit in the common ancestor followed by independent origins of predatory feeding in M. teleius and in the arion group. If $M$. nausithous was treated as "intermediate" between predators and cuckoos, this intermediate habit was optimized as ancestral for the teleius-arion clade as a whole, followed by two changes to the predatory habit in $M$. teleius and in the arion group, while the basal Maculinea habit remained equivocal.

The three main groups within the Maculinea clade are associated with distinct plant families (no. 80; Fig. 4B): the alcon group with Gentianaceae, the teleius group with Rosaceae, and the arion group with Lamiaceae, with a derived shift to related Gentianaceae and Campanulaceae in Phengaris daitozana. These families belong to two distinct clades of angiosperms (Angiosperm Phylogeny Group, 2003), Asteridae (Gentianaceae, Lamiaceae and Campanulaceae) and Rosidae (Rosaceae). The situation at the base of the Maculinea clade is ambiguous, but all other deeper-node ancestors within the Glaucopsyche section fed on various rosid families.

The common ancestor of the Maculinea clade was likely hygrophilous, and two switches to xerophilous
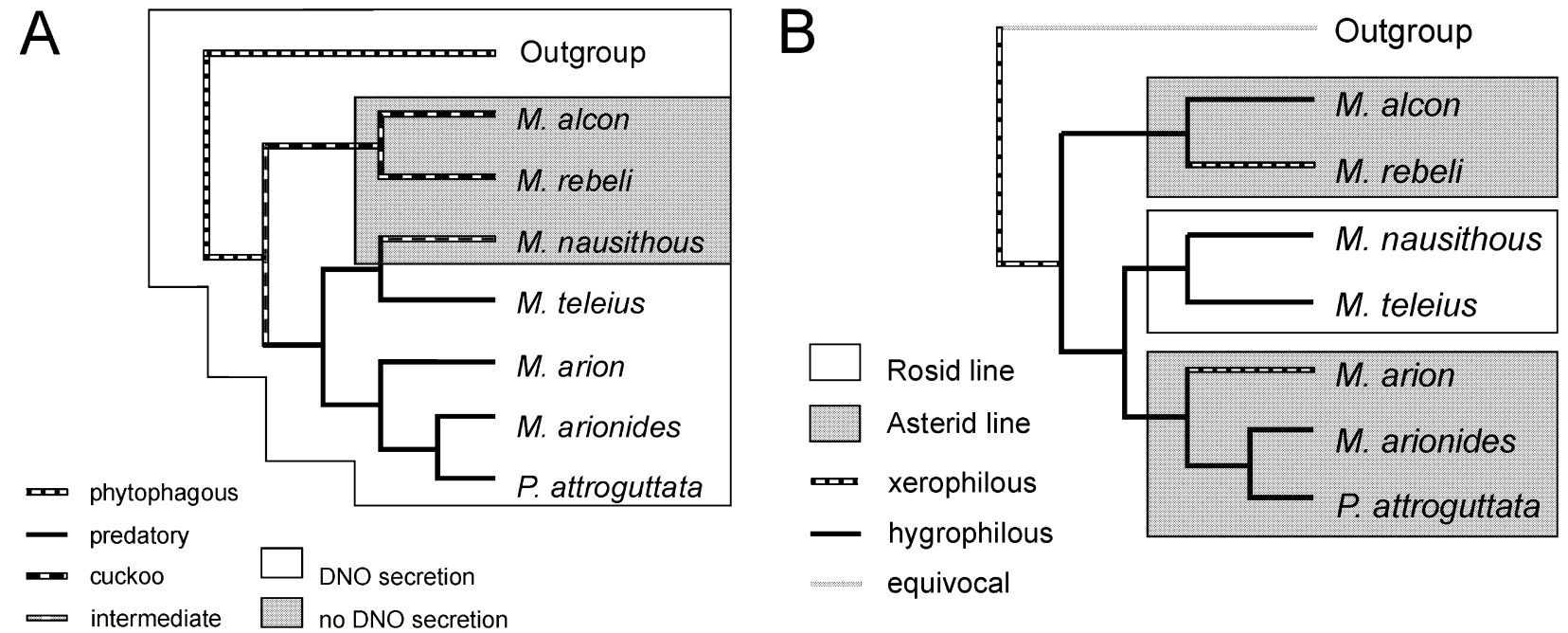

Fig. 4. Evolution of the life history traits of Maculinea butterflies and their relatives. Only the species for which states of all relevant characters are reliably well-known are included (see Table 1), but the overall topology of the tree including all terminals (Figs 2 \& 3) is preserved. (A) Myrmecophily. M. nausithous is optimized as a modified predatory species (see "Evolution of life histories"). (B) Host plants and habitat associations. Rosids and asterids are two well-supported clades of eudicot angiosperm plants (see Angiosperm Phylogeny Group, 2003): Fabaceae and Rosaceae are included in the former, Lamiaceae, Gentianaceae, and Campanulaceae in the latter. In some cases, character-state optimization is derived from the all-species tree (Fig. 3). 
habits occurred (no. 90), one in $M$. rebeli and the other in $M$. arion. All deeper-node ancestors within the Glaucopsyche section were xerophilous.

Therefore, although it seems certain that the ancestor of the Maculinea clade used DNO secretions during the adoption ritual, other arguments for the ancestral predatory habit in the Maculinea clade (phylogenetic distribution of feeding habits, assumed sister-group relationship of Maculinea and Phengaris, Lamiaceae as ancestral host plants, and origin of Maculinea in xeric habitats) did not withstand the scrutiny of our cladistic analysis.

\section{Discussion}

\section{Phylogeny and classification of Maculinea and Glaucopsyche section}

All species of Maculinea seem to form a clade that is well differentiated from the other taxa that had been, by different authors, considered congeneric, such as Glaucopsyche, Caerulea and Iolana. The clade splits into three main lineages corresponding, as far as the taxa traditionally classified as Maculinea are concerned, to the groupings proposed by Sibatani et al. (1994). All the putatively subspecific taxa of $M$. arion and $M$. teleius, respectively, form monophyletic groups with their nominal forms (Fig. 3). M. arionides seems to be paraphyletic, as its putative island subspecies $M$. arionides takamukui from Japan might be a separate species, distinguished by a thick apophysis posterior in the female genitalia and by the absence of spot A3 on the ventral forewing. The West Palaearctic M. alcon alcon is closer to European $M$. rebeli than to Asian taxa of $M$. alcon s. lat. "M. alcon" is then paraphyletic, and $M$. rebeli should possibly lose its full species status. Naturally, the precise relationships among terminal taxa in the present cladogram may be affected by the paucity of character data for some Asian taxa (see Appendix 2). Moreover, the closely related taxa are likely to experience similar selection pressures and to respond to them by parallel adaptation. Some of the relationships between the species (and even more between the subspecific terminals) could easily be due to abundant homoplasies (compare the exceptional non-homoplastic synapomorphies in Fig. 3).

The position of Phengaris, which is deeply nested within Maculinea in the combined tree, close to "M. arionides" and M. arion, is quite surprising. Hence, Fiedler's (1998) "closest living relatives of Maculinea" [= Phengaris $]$ are, in fact, true Maculinea species, which is corroborated by the wing venation and parasitic association with the ants (Fig. 3). It follows that preserving the generic name Phengaris renders Maculinea paraphyletic, and since Phengaris Doherty, 1891 is an older name than Maculinea Van Eecke, 1915, the taxonomy and nomenclature of "Maculinea" will need a thorough revision.

However, such formal actions for endangered taxa could seriously affect conservation policy, and we refrain from a formal reclassification of the Polyommatini at both genus- ("Glaucopsyche", "Maculinea") and species-rank ("M. arionides", M. takamukui?, "M. alcon", $M$. rebeli?) levels until additional data are available. The molecular data will probably add to our understanding of Maculinea phylogeny (see http:// www.macman-project.de; T. Als, D. Nash and K. Pecsenye, pers. comm.), especially in elucidating the terminal relationships within individual lineages. Since morphological and molecular evidence are two autonomous sources of data for reconstructing phylogenies (Freudenstein et al., 2003), the confrontation and combination of different data matrices may corroborate or falsify the validity of the present results (see VaneWright, 2003; Wahlberg and Nylin, 2003).

In the same vein, our results regarding the relationships among the Glaucopsyche section outgroups must be viewed as only preliminary. The character sampling was affected by the necessity to find traits suitable for finer-level differentiation within Maculinea, including characters for putative subspecies, not for an analysis of intergeneric relationships. As a result, many of the traits were not applicable to non-Maculinea outgroups (cf. Appendix 2). In addition, the mutual positions of outgroups would likely change by including more nonMaculinea terminals and more "genus-level" characters. It still seems likely at this stage that there is no support for the two lineages proposed by Hesselbarth et al. (1995), viz., Scolitantiditi and Glaucopsychiti, and that Glaucopsyche is probably paraphyletic and does not represent a single sister group to the Maculinea clade.

\section{Origin of the parasitic myrmecophily}

The optimization of larval feeding on the tree habits did not support the earlier view by Fiedler (1998), that the predatory habit preceded the cuckoo habit in the evolution of Maculinea. However, it did not support any alternative view either, as scenarios of earlier origin of the cuckoo habit, and of two independent origins of the two habits, required identical numbers of evolutionary steps (Fig. 4A). The only firm conclusion is that cuckoo and predatory representatives of Maculinea form two distinct clades. The ambiguity with the evolution of cuckoo versus predatory habit might be resolved by an improved understanding of the life history of the little known East Palearctic M. kurentzovi (cf. Sibatani et al., 1994; Tuzov et al., 2000) and the problematic $M$. nausithous, basal species of the teleius group.

On the other hand, Fiedler (1998) was correct with regard to plesiomorphy of the regular use of DNO 
secretions during adoption. Moreover, the finding that $M$. nausithous is not particularly closely related to the alcon group suggests that the reduction in the DNO secretions may have evolved twice independently.

The Lamiaceae-feeding predatory taxa of Maculinea are derived and not closely related to the more basal Lamiaceae feeders within the Glaucopsyche section (e.g., Pseudophilotes). The association with Lamiaceae cannot therefore contribute to a resolution of the ancestrality of predatory versus cuckoo strategies. The tree topology, and particularly the derived position of Phengaris, also refutes the proposal by Fiedler (1998) that ancestors of Maculinea evolved in mountain steppe-like habitats with a short vegetation season. The ancestral habitats of Maculinea were rather hygrophilous, and the (repeated) colonization of the more dry habitats (M. rebeli, $M$. arion) is derived. However, even taxa as closely related as $M$. alcon alcon and $M$. rebeli differ with respect to living at dry versus wet sites. This also seems to be the case in the putatively subspecific taxa of $M$. teleius, whose East-Asian populations reportedly inhabit "dry meadows" (Asahi et al., 1999). The association with humid versus dry habitat conditions thus seems to be rather plastic in Maculinea.

Certainly less plastic is the association with host plants, as the three main lineages of the Maculinea clade exhibits conservatism on the level of plant families (the highly derived Phengaris daitozana is a single exception). On the other hand, remarkable shifts between phylogenetically distant host plants had to occur at the deepest nodes of Maculinea phylogeny (Fig. 4B). Equally remarkable is the taxonomic diversity of host plant use by non-parasitic taxa of the Glaucopsyche section: Iolana, Glaucopsyche, Shijimiaeoides and Sinia feed on Fabaceae; Scolitantides and Philotes on Crassulaceae; Pseudophilotes on Lamiaceae; Euphilotes and Praephilotes on Polygonaceae; and Turanana on Plumbaginaceae. However, each of the non-parasitic genera feed on a single plant family (Fiedler, 1994) and none exhibits the remarkable diversity of the host-plant associations found in Maculinea.

Recent studies on nymphalid butterflies have demonstrated that switches towards taxonomically distant plants had been frequent in their evolution, and that their directions depended on plant functional traits, such as chemical composition and plant architecture, rather than on phylogenetic proximity (e.g., Janz et al., 2001; Wahlberg, 2001). It is worth asking why Maculinea exhibits such a high diversity in basal nodes combined with strict oligophagy within individual branches. It is plausible that any oviposition-site mistakes, considered as prerequisites for host shifts in herbivorous insects (e.g., Renwick and Chew, 1994; Larsson and Ekbom, 1995), may be more costly in species with an obligate association with ants if the host ants are missing near the erroneously visited host. On the other hand, the parasitic myrmecophily may occasionally relax the strict dependency on a particular host plant if the proper ant species is present (recall that Maculinea larvae are phytophagous for only a short time compared to the permanently phytophagous Lepidoptera). In evolutionary time, this might cause the strict host plant conservatism within individual subclades of Maculinea, combined with the radical rearrangement of host plant associations at the base of the whole clade due to rare switches to phylogenetically distant plants. Notably, tropical lycaenids that exhibit mutualistic myrmecophily are often polyphagous with respect to host plants, whereas the Afrotropical genus Lepidochrysops Hedicke, 1923, whose representatives employ a Maculinea-type parasitic myrmecophily, exhibits oligophagy at the species level while feeding on wide range of plant families (Fiedler, 1995).

The radical rearrangements of host plant association in separate lineages of the Maculinea clade also allow for possible repeated emergence of the cuckoo habit in the $M$. nausithous and $M$. alcon groups. We are in agreement with Fiedler (1998), in that it seems reasonable that after a mistaken oviposition, that a predatory species with less developed chemical mimicry and active DNO secretion should be more likely to be adopted than a cuckoo species.

\section{Acknowledgements}

We thank J. Beneš, D. Boukal, A. Pavlíčko and Z. Weidenhoffer for the loan of specimens, D. Nash, T. Als and K. Pecsenye for discussing some of their preliminary results from the molecular study of phylogeny of Maculinea with us, J. Settele for introducing us to the EU Maculinea Management programme, and M. Sweney for improving the English of the manuscript. K. Fiedler and one anonymous referee contributed valuable suggestions to a previous version of the manuscript. K. Fiedler, V. Hula and M. Munguira helped us obtain some rare literature, and M. Yanagimoto translated some texts from Japanese. The study was supported by grants from the Czech Ministry of Education (no. 123100003), the Academy of Sciences of the Czech Republic (no. K6005114) and the Grant Agency of the Czech Republic (no. 206/03/H034).

\section{References}

Agenjo, R., 1967. Morfología y distribución geográfica en España de la 'Escamas azules' Glaucpsyche melanops (B., 1828) (Lep. Lycaenidae). Eos, 43, 13-20.

Akino, T., Knapp, J.J., Thomas, J.A., Elmes, G.W., 1999. Chemical mimicry and host specificity in the butterfly Maculinea rebeli, a social parasite of Myrmica ant colonies. Proc. R. Soc. Lond. B Biol. 266, 1419-1426. 
Als, T.D., Nash, D.R., Boomsma, J.J., 2002. Geographical variation in host-ant specificity of the parasitic butterfly Maculinea alcon in Denmark. Ecol. Entomol. 27, 403-414.

Angiosperm Phylogeny Group, 2003. An update of the Angiosperm Phylogeny Group classification for the orders and families of flowering plants: APG II. Bot. J. Linn. Soc. 141, 399-436.

Asahi, J., Kanda, S., Kawata, M., Kohara, Y., 1999. The Butterflies of Sakhalin in Nature. Hokkaido Shimbun Press, Sapporo, Japan.

Bálint, Z., 1989. Hairstreaks, coppers and blues from Mongolia (Lep., Lycaenidae). Atalanta, 19, 87-100.

Beldade, P., Koops, K., Brakefield, P.M., 2002. Modularity, individuality, and evo-devo in butterfly wings. Proc. Natl. Acad. Sci. USA, 99, 14262-14267.

Beneš, J., Konvièka, M., Dvoøák, J., Fric, Z., Havelda, Z., Pavlièko, A., Vrabec. V., Weidenhoffer, Z., 2002. Butterflies of the Czech Republic: Distribution and Conservation. Spoleènost pro ochranu motýlù, Praha.

Berlov, O., 2001. Tsvetnoi Atlas-Opredelitel' Dnevnykh Babochek Basseina Ozera Baikal [Coloured Determination Key of the Butterflies of the Lake Baikal Basin]. URL: http://babochki.narod.ru.

Bernardi, G., 1972. Note sur la variation géographique de l'armure génitale mâle des Iolana (Lep. Lycaenidae). B. Soc. Entomol. Fr. 77, 160-167.

Beuret, H., 1958. Zur systematischen Stellung einiger wenig bekannter Glaucopsychidi (Lep., Lycaenidae). Mitt. Entomol. Ges. Basel, 8, 81-100.

Brakefield, P.M., 2003. The power of evo-devo to explore evolutionary constraints: experiments with butterfly eyespots. Zoology, 106, 283-290.

Cano, J.M., 1981. Similitudes biologicas y diferentias ecologicas entre Glaucopsyche alexis (Poda) y Glaucopsyche melanops (Boisduval). (Lep. Lycaenidae). B. Estation Centr. Ecol. 10, 59-70.

D'Abrera, B., 1993. Butterflies of Holarctic region III. Nymphalidae (Concl.), Libytheidae, Riodinidae \& Lycaenidae. Hill House, Black Rock, pp. 336-524.

Ebert, G., Rennwald, E., 1991. Die Schmetterlinge Baden-Württembergs. Band 1: Tagfalter 2. Eugen Ulmer, Hohenheim.

Elfferich, N.W., 1998. New facts on the life history of the dusky large blue Maculinea nausithous (Lepidoptera: Lycaenidae) obtained by breeding with Myrmica ants in plaster nests. Deinsea, 4, 97-102.

Eliot, J.N., 1973. The higher classification of the Lycaenidae (Lepidoptera): a tentative arrangement. Bull. Br. Mus. Nat. Hist. (Entomology), 28, 373-505.

Elmes, G.W., Akino, T., Thomas, J.A., Clarke, R.T., Knapp, J.J., 2002. Intespecific differences in cuticular hydrocarbon profiles of Myrmica ants are sufficiently consistent to explain host specificity by Maculinea (large blue) butterflies. Oecologia, 130, 525-535.

Elmes, G.W., Thomas, J.A., 1992. Complexity of species conservation in managed habitats: interaction between Maculinea butterflies and their ant hosts. Biodivers. Conserv. 1, 155-169.

Elmes, G.W., Thomas, J.A., Munguira, M.L., Fiedler, K., 2001. Larvae of lycaenid butterflies that parasitize ant colonies provide exceptions to normal insect growth rules. Biol. J. Linn. Soc. 73, 259-278.

Elmes, G.W., Thomas, J.A., Wardlaw, J.C., 1991. Larvae of Maculinea rebeli, a large-blue butterfly, and their Myrmica host ants: wild adoption and behaviour in ant-nests. J. Zool. 223, 447-460.

Emmet, A.M., Heath, J., 1989. The Moths and Butterflies of Great Britain and Ireland, Vol. 7, Part 1. Hesperiidae-Nymphalidae. The Butterflies. Harley Books, Colchester, UK.

Fiedler, K., 1990. New information on the biology of Maculinea nausithous and M. teleius. Nota Lepid. 12, 246-256.

Fiedler, K., 1991. Systematic, evolutionary, and ecological implications of myrmecophily within the Lycaenidae [Insecta: Lepidoptera: Papilionoidea]. Bonner Zoologische Monographien, no. 31.

Fiedler, K., 1994. Lycaenid butterflies and plants: is myrmecophily associated with amplified hostplant diversity? Ecol. Entomol. 19, $79-82$.
Fiedler, K., 1995. Lycaenid butterflies and plants - is myrmecophily associated with particular hostplant preferences? Ethol. Ecol. Evol. 7, 107-132.

Fiedler, K., 1998. Lycaenid-ant interactions of the Maculinea type: tracing their historical roots in a comparative framework. J. Insect Conserv. 2, 3-14.

Freudenstein, J.V., Pickett, K., Simmons, M.P., Wenzel, J.W., 2003. From basepairs to birdsongs: phylogenetic data in the age of genomics. Cladistics, 19, 333-347.

Fukuda, H., Hama, E., Kuzuya, T., Takahashi, A., Takahashi, M., Tanaka, B., Tanaka, H., Wakabayashi, M., Watanabe, Y., 1985. The Life Histories of Butterflies in Japan, Vol. III. Hoikusha, Osaka, Japan.

Goloboff, P., 1999. NONA (NO NAME), Version 2.0. Published by the author, Tucumán, Argentina. URL: http://www.cladistics.com/ aboutNona.htm.

Grant, T., Kluge, A.G., 2003. Data exploration in phylogenetic inference: scientific, heuristic, or neither. Cladistics, 19, 379-418.

Hemming, A.F., 1931. Revision of the genus Iolana, Bethune-Baker (Lepidoptera, Lycaenidae). Trans. Entomol. Soc. Lond. 79, 323333.

Hesselbarth, G., Van Oorschot, H., Wagener, S., 1995. Die Tagfalter der Türkei unter Berücksichtingung der angrenzenden Länder. Selbstverlag Sigbert Wagener, Bocholt.

Higgins, L.G., 1975. The Classification of European Butterflies. Collins, London.

Hochberg, M.E., Clarke, R.T., Elmes, G.W., Thomas, J.A., 1994. Population dynamic consequences of direct and indirect interactions involving a large blue butterfly and its plant and red hosts. J. Anim. Ecol. 63, 375-391.

Igarashi, S., Fukuda, H., 2000. The Life History of Asian Butterflies, 2. Tokai Daigaku Shuppankai, Tokyo.

Inomata, T., 1990. Keys to the Japanese Butterflies in Natural Color. Hokuryukan, Tokyo.

Jaksic, P.N., 1998. Male Genitalia of Butterflies on the Balkan Peninsula with a Checklist (Lepidoptera: Hesperioidea and Papilionoidea). Slamka, Bratislava.

Janz, N., Nyblom, K., Nylin, S., 2001. Evolutionary dynamics of hostplant specialization: a case study of the tribe Nymphalini. Evolution, 55, 783-796.

Karsholt, O., Razowski, J., 1996. The Lepidoptera of Europe: a Distributional Checklist. Apollo Books, Stenstrup.

Kawazoe, A., Wakabayshi, M., 1976. Colored Illustrations of the Butterflies of Japan. Hoikusha Publishing, Osaka.

Korshunov, Y., Gorbunov, P., 1995. Dnevnye Babochki Aziatskoi Chasti Rossii: Spravochnik [Butterflies of the Asian Part of Russia: a Handbook]. Ural University Press, Ekaterinburg.

Kudrna, O., 2001. Miscellaneous notes on the taxonomy of four European butterflies (Lepidoptera: Rhopalocera). Entomol. Gaz. 52, 253-261.

Kurentsov, A.I., 1970. Bulavousye Cheshuekryle Dalnego Vostoka SSSR: Opredelitel' [Rhopaloceran Butterflies of Far East of the USSR: A Key to Determination.] Nauka, Leningrad.

Larsson, S., Ekbom, B., 1995. Oviposition mistakes in herbivorous insects: confusion, or a step towards a new host plant? Oikos, 72, $155-160$.

Leimar, O., Axén, A., 1993. Strategic behaviour in an interspecific mutualism: interactions between lycaenid larvae and ants. Anim. Behav. 46, 1177-1182.

Mattoni, R.H.T., 1977. The Scolitantidini I: Two new genera and a generic rearrangement (Lycaenidae). J. Res. Lepid. 16, 223-242.

Mattoni, R.H.T., [1981] 1979. The Scolitantidini II. The World's smallest butterfly? Notes on Turanana, and a new genus and species from Afghanistan. (Lycaenidae). J. Res. Lepid. 18, 256-264.

Mattoni, R.H.T., Fiedler, K., 1991. On the functional foreleg tarsus in Caerulea males (Lepidoptera: Lycaenidae: Polyommatini). J. Res. Lepid. 30, 289-296. 
Nijhout, H.F., 1991. The Development and Evolution of Butterfly Wing Pattern. Smithsonian Institution Press, Washington, DC.

Park, K.T., Kim, S.S., 1997. Atlas of Butterflies (Lepidoptera). Insects of Korea, Series 1. Korea. Research Institute of Bioscience and Biotechnology and Center for Insect Systematics, Chuncheon.

Pierce, N.E., Braby, M.F., Heath, A., Lohman, D.J., Mathew, J., Rand, D.B., Travassos, M.A., 2002. The ecology and evolution of ant association in the Lycaenidae (Lepidoptera). Annu. Rev. Entomol. 47, 733-771.

Renwick, J.A.A., Chew, F.S., 1994. Oviposition behavior in Lepidoptera. Annu. Rev. Entomol. 39, 377-400.

Shirozu, T., 1960. Butterflies of Formosa in Color. Hoikosha, Osaka, Japan.

Sibatani, A., Saigusa, T., Hirowatari, T., 1994. The genus Maculinea van Eecke, 1915 (Lepidoptera: Lycaenidae) from East Palaearctic Region. Tyo to Ga, 44, 157-220.

Stankiewicz, A., Sielezniew, M., 2002. Host specificity of Maculinea teleius Bgstr. and M. nausithous Bgstr. (Lepidoptera: Lycaenidae): the new insight. Ann. Zool. 52, 403-408.

Steiner, F.M., Sielezniew, M., Schlick-Steiner, B.C., Höttinger, H., Stankiewicz, A., Górnicki, A., 2003. Host specificity revisited: new data on Myrmica host ants of the lycaenid butterfly Maculinea rebeli. J. Insect Conserv. 7, 1-6.

Thomas, J.A., 1980. Why did the large blue become extinct in Britain? Oryx, 15, 243-247.

Thomas, J.A., 1994. The ecology and conservation of Maculinea arion and other European species of large blue. In: Pullin, A.S. (Ed.), Ecology and Conservation of Butterflies. Chapman \& Hall, London, pp. 180-196.

Thomas, J.A., Elmes, G.W., 1998. Higher productivity at the cost of increased host-specificity when Maculinea butterfly larvae exploit ant colonies through trophallaxis rather than by predation. Ecol. Entomol. 23, 457-464.

Thomas, J.A., Elmes, G.W., Wardlaw, J.C., Woyciechowski, M., 1989. Host specificity among Maculinea butterflies in Myrmica ant nests. Oecologia, 79, 452-457.

Thomas, J.A., Munguira, M.L., Martin, J., Elmes, G.W., 1991. Basal hatching by Maculinea butterfly eggs: a consequence of advanced myrmecophily? Biol. J. Linn. Soc. 44, 175-184.

Tolman, T., Lewington, R., 1997. Butterflies of Britain and Europe. Harper and Collins, London.

Tuzov, V.K., Bogdanov, P.V., Churkin, S.V., Devyatkin, A.L., Danchenko, A.V., Murzin, V.S., Samodurov, G.D., Zhdanko, A.B., 2000. Guide to the Butterflies of Russia and Adjacent Territories (Lepidoptera, Rhopalocera), Vol. 2: Libytheidae, Danaidae, Nymphalidae, Riodinidae, and Lycaenidae. Pensoft, Sofia.

Van Swaay, C.A.M., Warren, M.S., 1999. Red Data Book of European Butterflies (Rhopalocera). Nature and Environment Series No. 99. Council of Europe, Strasbourg.

Vane-Wright, R.I., 2003. Evidence and identity in butterfly systematics. In: Boggs, C.L., Watt, W.B., Ehrlich, P.R. (Eds.), Butterflies: Ecology and Evolution Taking Flight. University of Chicago Press, Chicago, pp. 477-513.

Wahlberg, N., 2001. The phylogenetics and biochemistry of host-plant specialization in Melitaeine butterflies (Lepidoptera: Nymphalidae). Evolution, 55, 522-537.

Wahlberg, N., Nylin, S., 2003. Morphology versus molecules: resolution of the positions of Nymphalis, Polygonia, and related genera (Lepidoptera: Nymphalidae). Cladistics, 19, 213-223.

Wardlaw, J.C., Elmes, G.W., Thomas, J.A., 1998. Techniques for studying Maculinea butterflies. II. Identification guide to Myrmica ants found on Maculinea sites in Europe. J. Insect Conserv. 2, 119127.

Wardlaw, J.C., Thomas, J.A., Elmes, G.W., 2000. Do Maculinea rebeli caterpillars provide vestigial mutualistic benefits to ants when living as social parasites inside Myrmica ant nests? Entomol. Exp. Appl. $95,97-103$.
Wynhoff, I., 1998a. Lessons from the reintroduction of Maculinea teleius and M. nausithous in the Netherlands. J. Insect Conserv. 2, $47-57$.

Wynhoff, I., 1998b. The recent distribution of the European Maculinea species. J. Insect Conserv. 2, 15-27.

\section{Appendix 1. List of characters and character states}

\section{Male terminalia}

0 . Genital length from lateral view (0) approximately equal to its height, (1) much wider than its height.

1. Vinculum (0) more or less straight, without a cranially protruding hump, (1) containing prominent cranially protruding hump.

2. Cranial outer angle of socius (0) approximately in the middle between saccus and socius, (1) closer to socius.

3. Hairs on socius in a lateral view ( 0 ) form a triangle, (1) form a band, that is slightly broadened on the ventral part of socius, (2) form a band that is not broadened on the ventral part of socius. Unordered.

4. A spike-like protrusion on ventral side of socius, viewed laterally (0) absent, (1) present.

5. Falx (0) long, its base extends the base of socius, (1) short, its base does not reach to the base of socius.

6 . Top of ring (0) not protruded, fused with uncus, (1) protruded, extending uncus.

7. Saccus (0) big, (1) very small.

8. Saccus (0) bend caudally, (1) straight or bend cranially.

9. Internal margin of valva, (0) parallel with external margin (1) dilated relative to external margin.

10. Outer margin of valva (0) more or less straight or weakly convex, (1) concave.

11. Ampulla protruding (0) from a middle position at outer margin of valva, (1) from the sharp angle between distal and lateral margins of valva.

12. Base of ampulla (0) wide and rounded externally, (1) narrow and not rounded externally.

13. Base of ampulla (0) smooth, (1) bearing a toothed tubercle.

14. Length of ampulla (0) shorter than $1 / 2$ of distal margin of valva, (1) as long as $1 / 2$ of distal margin of valva or slightly longer, (2) considerably longer than $1 / 2$ of distal margin of valva. Ordered.

15. Outer margin of ampulla (0) bearing teeth, (1) smooth.

16. Teeth on ampulla (0) disarranged, (1) arranged into lines running parallely with distal margin of ampulla.

17. Length of aedeagus (0) more than height of ring, (1) as long as height of ring or slightly shorter.

18. Length of Chapman's process (0) more than $3 / 4$ of the thorny part of ventral margin of vesica, (1) $3 / 4-1 / 4$ 
of the thorny part of ventral margin of vesica, (2) less than $1 / 4$ of the thorny part of ventral margin of vesica. Ordered.

19. Shape of Chapman's process (0) straight, (1) curved.

20. Width of distal part of aedeagus (just behind distal end of Chapman's process) (0) equal or longer than $2 / 3$ of its length, (1) less then $1 / 2$ of its length.

21. Spines on vesica (0) small, (1) large.

22. Laterodistal margin of dorsal sclerite of aedeagus (0) shorter than the width of aedeagus just proximally to vesica, (1) as long as width of aedeagus proximally to vesica, (2) longer than width of aedeagus proximally to vesica. Ordered.

23. Laterodistal margin of dorsal sclerite of aedeagus (0) not dilated, (1) dilated.

24. Laterodistal margin of dorsal sclerite of aedeagus (0) without spines, (1) covered by spines distally.

25. Lateroproximal margin of dorsal sclerite of aedeagus (0) rounded, (1) sharply indented.

26. Distal dilation of long laterodistal process of dorsal sclerite of aedoeagus (0) dilates sharply far behind a middle of length of the process, (1) dilates gradually, beginning from a mid-position of the length of the process.

27. Angle between dorsal branches of juxta (0) approximately $50^{\circ}$ or less, (1) $60^{\circ}-70^{\circ}$, (2) $70^{\circ}$ or more. Ordered.

28. Inner angle of juxta (0) sharply V-shaped, (1) smoothly U-shaped.

29. An outgrowth inside inner angle of juxta (0) absent, (1) present.

30. Stalk of juxta (0) not dilating laterally, (1) dilating laterally into a bulge-like shape.

\section{Female terminalia}

31. Caudal portion of ductus bursae (0) not broadened, (1) broadened.

32. Lodix (0) square, (1) rectangular.

33. Ventral sclerite of VI abdominal segment (0) short and square, (1) oblong and triangular.

34. Genital plate (0) tongue-shaped or triangual, (1) semicircular.

35. Apophysis posterioris (0) relatively thick, (1) relatively slender.

36. Length of papilla analis (0) $0.34-0.39$ of VIII tergit, (1) 0.45 of VIII tergit, (2) $0.46-0.54$ of VIII tergit. Ordered.

\section{Eggs and hatching}

37. Hatching (0) terminal or lateral, (1) basal.

38. Eggs-laying substrates (0) sheltered, (1) exposed.

39 . Width of chorion (0) less then $5 \mu \mathrm{m}$, (1) more than $5 \mu \mathrm{m}$.
Eyes

40. Eyes (0) smooth, (1) hairy.

Palps

41. Length of palps (0) shorter than 1.6 of height of head, (1) longer.

42. Length of third segment of palps (0) short, $c .1 / 4$ of length of the second segment, (1) longer, $c .1 / 2$ of length of the second segment.

\section{Antennae}

43. Ventral side of terminal part of antennae (0) darkly unicoloured, (1) dark with a lightly colored elongate strip.

44. Tip of antennae (0) darkly unicoloured, (1) bearing lightly colored subterminal ring.

Wings, both sexes

45. Stalk of veins $7+8$ arises $(0)$ at the distal end of discal cell, (1) before distal end of discal cell.

46. Ocellar systems on ventral wings (0) absent, (1) present.

47. Marginal systems on ventral wings (0) absent, (1) present.

Ventral forewing, both sexes

48. Spot A3 (0) absent, (1) present.

49. Spot F3 (0) markedly shifted basally, (1) not markedly shifted basally.

50. Spots B3, C3 and D3 (0) arranged quasi-linearly, (1) in arch-like arrangement.

51. Spots of ocellar system (0) of the same size as spots of other systems, (1) markedly enlarged with respect to spots of other systems.

52. Average forewing length (0) less then $20 \mathrm{~mm}$, (1) more then $20 \mathrm{~mm}$. Coded as ambiguity in species varying around the threshold.

Ventral hindwing, both sexes

53. Spot X (0) absent, (1) present.

54. Spot $S(0)$ absent, (1) present.

55. Spot W (0) absent, (1) present.

56. Spot F3 (0) markedly shifted basally, (1) not markedly shifted basally.

\section{Ventral coloration, both sexes}

57. Orange colour between ocellar and marginal systems (0) absent, (1) present.

58. Blue scales on the hind wing (0) absent, (1) present. 
59. Basal colour between medial system 3 and ocelar system 2 (0) identical to other parts of the wing, (1) containing white triangles.

60 . Fringes on fore wing (0) uniformly coloured, (1) chequered black and white.

61. Fringes on hind wing (0) uniformly coloured, (1) chequered black and white.

62. Basal colour (0) whitish gray, (1) dark gray, (2) dark brown. Unordered.

\section{Ventral forewing, males}

63. Spot T (0) absent, (1) present.

64. Spot $\mathrm{S}(0)$ absent, (1) present.

65. Spot G3 (0) absent, (1) present.

Ventral hindwing, males

66. Spot T (0) absent, (1) present.

67. Spot V (0) absent, (1) present.

Dorsal forewing, males

68. Spot R (0) absent, (1) present.

69. Spot S (0) absent, (1) present.

\section{Dorsal coloration, males}

70. Blue colour (0) extending up to wing margin, (1) surrounded by wide dark marginal strip, (2) substantially reduced. Unordered.

\section{Ventral forewing, females}

71. Spot T (0) absent, (1) present.

72. Spot $S(0)$ absent, (1) present.

73. Spot G3 (0) absent, (1) present.

\section{Ventral hindwing, females}

74. Spot T (0) absent, (1) present.

\section{Dorsal forewing, females}

75. Spot A3 (0) absent, (1) present.

76. Spot $\mathrm{S}(0)$ absent, (1) present.

\section{Dorsal hindwing, females}

77. Ocellar system on dorsal hind wing (0) absent, (1) present.

\section{Dorsal coloration, females}

78. Orange colour on between ocellar and marginal systems (0) absent, (1) present.

79. Blue colour on the dorsal side of wings ( 0 ) absent, (1) at least some patches of blue scales, (2) present on more then half of wing surface. Unordered

\section{Ecology and life history}

80. Larval host plant (0) Fabaceae, (1) Rosaceae, (2) Lamiaceae, (3) Gentianaceae. Unordered

81. Tentacle organs (0) absent, (1) present.

82. Myrmecophilous habit (0) no stable ant associations, (1) facultative ant mutualism, (2) parasitism. Ordered.

83. Host ant specificity (0) weak, host ants from more families, (1) strong, hosts ants from subfamily Myrmicinae.

84. Adoption (0) fast, without elaborate ritual, (1) slow, with a ritual.

85. Secretion from dorsal nectary organs during adoption (0) absent, (1) always present.

86. Feeding habit of caterpillars within ant nests (0) cuckoo, they are fed by workers via regurgitation, (1) predatory. M. nausithous is generally considered predatory (Thomas and Elmes, 1998), but part of this evidence originated from rearing with unnatural ants (Elfferich, 1998). Besides, there are anecdotal reports of larvae being actively fed by ants (mentioned in Elmes et al., 2002), or being tended by them when the nest was disturbed (Stankiewicz and Sielezniew, 2002). We coded the species' habit in four ways: (i) as a "predatory" species, (ii) as a "cuckoo" species, (iii) as an intermediate $(0=$ predatory, $1=M$. nausithous, $2=$ cuckoo; ordered); (iv) as a polymorphic ("[01]") trait (Appendix 2; but see Grant and Kluge, 2003; for arguments against polymorphic character coding).

87. During phytophagous stage, larvae feed on (0) vegetative organs or both vegetative and reproductive organs of plants, (1) only on reproductive organs of plants.

88. Voltinism (0) only one generation per year, (1) ability to form more then one generation per year.

89. Overwintering stage (0) caterpillar, (1) pupa.

90. Habitat of the species (0) xerophilous, (1) mesophilous to hygrophilous. 


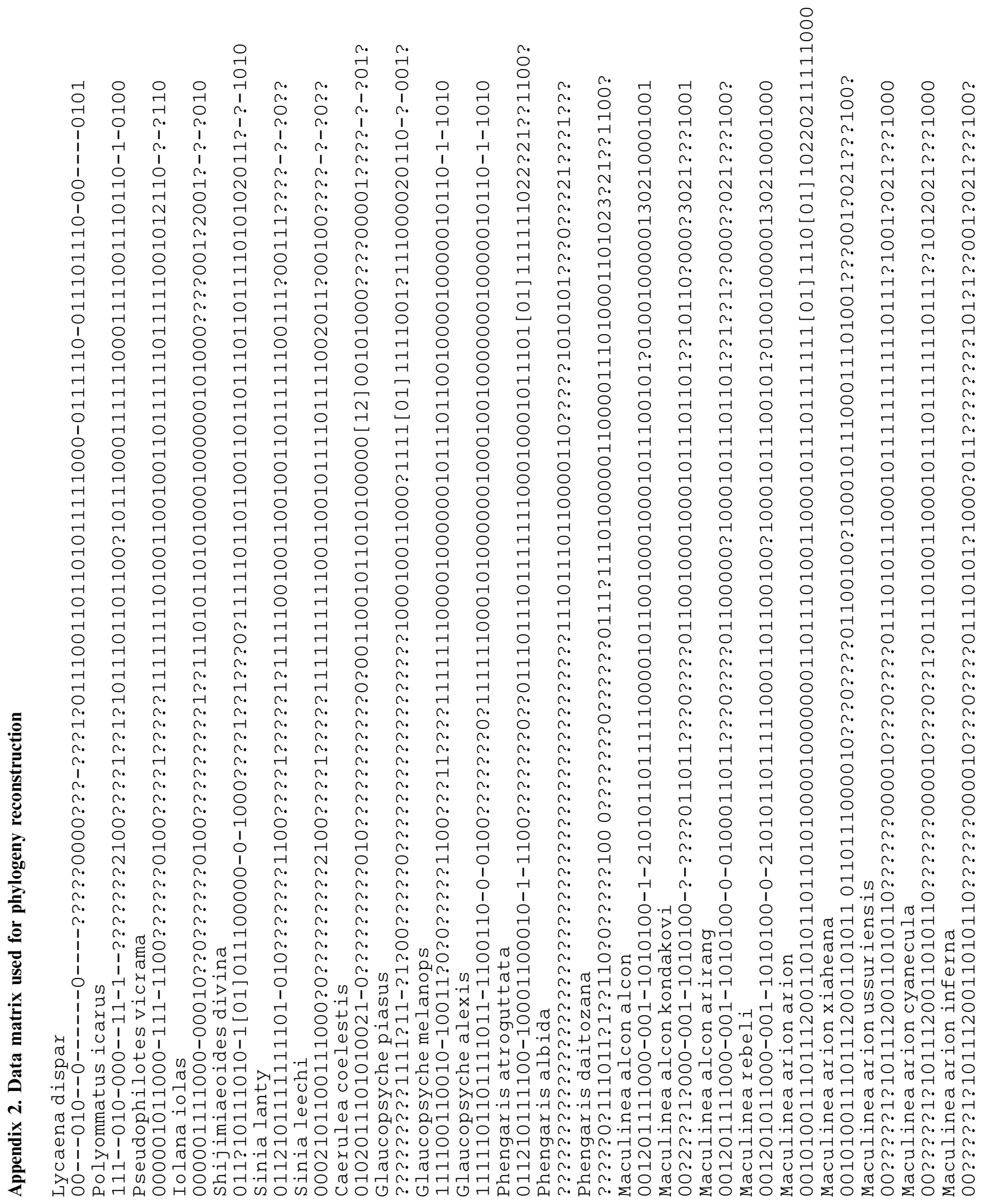




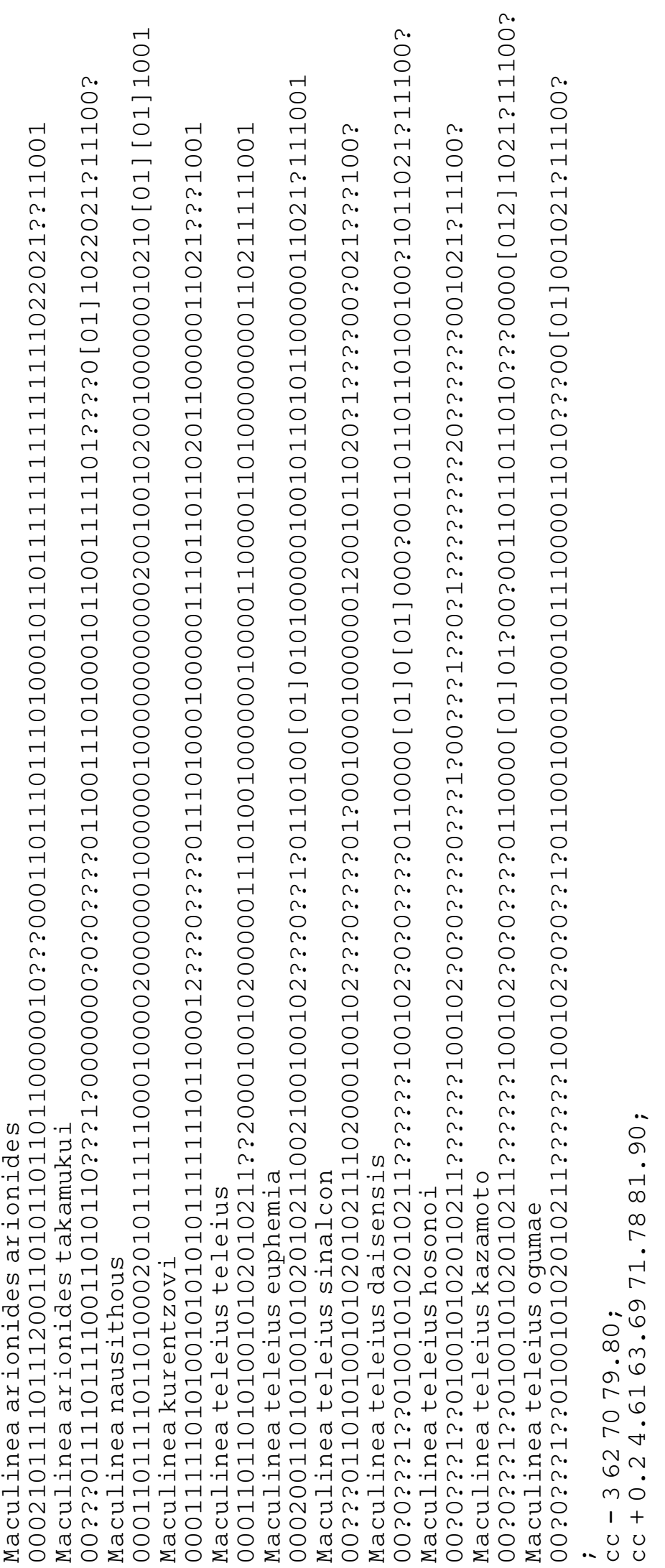

